\title{
The techniques of using new cladding systems \& construction materials to protect structures against blast waves and fragments
}

\author{
Hesham Ashraf El-Kadi * \\ Mohamed Ali Barakat **
}

\begin{abstract}
.
Protected structures are the sorts of structures that have to be given an acceptable percentage of protection against various hazards especially terrorist attacks using explosives. These sorts of structures include important structures such as embassies, governmental buildings, etc.
\end{abstract}

The approach of designing these sorts of building varies from the traditional architecture design process that depends on how far the architect can integrate both the functional and the aesthetic values in his/her design concept, as a new criterion appeared that influenced the traditional design process and offered it a new dimension that is "The protection against terrorism".

The new design process has to be a joint responsibility between several specialists (Urban designers, architects, material properties and civil engineers) each has a role (technique) in reducing the effect of the threat on structure.

The aim of this paper is to present some of the new techniques using construction and finishing materials that can offer a significant reduction in the effect of blast waves and fragments without affecting the structure function or the user's psychology.

KEY WORDS.

Architecture Engineering, Protection, Cladding systems.

\section{EFFECT OF EXPLOSIVES ON STRUCTURES.}

When an explosive is detonated, it will produce three primary effects that create damage in the area surrounding the explosion [R1]. These effects are:-

a) Blast effect.

b) Fragmentation effect.

c) Incendiary thermal effect.

\section{a) Blast effect.}

When an explosion charge is detonated, very hot expanding gases are formed. These gases exert pressures on the atmosphere surrounding the point of detonation and rush away in a spherical pattern from the point of detonation at high velocities, compressing the surrounding air forming an atomic vacuum in place of air. This giant wave called the 
blast pressure wave. This compressed layer of air becomes visible in some cases as a white, rapidly expanding circle, known as the shock front. As the shock front, followed by the positive pressure wave, moves outward the detonation point, it applies a sudden, hammering blow to any object in its path, followed instantly by the strong winds of the positive pressure wave itself. The shock front shatters any object in its path, and the positive pressure wave gives it a cyclone like, sudden and violent push.

\section{b) Fragmentation effect.}

When the explosive materials were detonated, it's not only the effect of blast pressure that will power away from detonation point, but also the fragmentation of broken things that will propel with high velocity, and in straight direction to blow any things in its path, or to fall on the ground when it losses its velocity.

\section{c) Incendiary thermal effect.}

A great amount of heat is released, causing the ambient temperature to be raised by several hundred degrees. This effect may produce secondary fires.

\section{EFFECT OF EXPLOSIVES ON PEOPLES.}

People exposed to explosions are subject to death and injury from several sources [R1], as follows;-
a) High pressure.
b) High temperature.
c) Fragmentations.

\section{TRADITIONAL DESIGN APPROACHES OF PROTECTED STRUCTURES.}

The traditional techniques to protect structures and peoples against terrorism and public disorder would have the following approaches [R2]:-

- A perimeter barrier strong enough to exclude all vehicles.

- A standoff area between the main building and the perimeter.

- Hiding the view of the main building from outside.

- A sterile zone for sensors and surveillance.

- Hardening of the main building to prevent collapse, fire, intrusion and injury from flying debris.

- Limiting accesses points, all of which are controlled.

These approaches, despite their validity, have some disadvantages as they may [R3]:

- Oppose the aspiration of the architect.

- Impede the activities, which the structure is designed to accommodate.

- Incur high construction cost, which may not be in function in case if the structure will not suffer any kind of threat.

- Psychologically influence the structure's users as they may convert the building to a type of fort or casemate.

\section{NEW DESIGN APPROACHES OF PROTECTED STRUCTURES [R4].}

The design process of protected structures has to be a joint responsibility, in which several specialists have to take part. Each specialist has his own role and ideas in 
reducing the effect of the threat on the structure to a certain limit that by combining all these design approaches together, the effect of the threat will be reduced to reach its minimum value. The sequence of the design process is so important in order to achieve a high percentage of protection.

A simple example for the new design process sequence can be in this form [R4] :

First step:
Second step:
Third step:
- Fourth step:
The landscape design (earth work).

The overall architectural concept of design.

Civil engineering analysis and design.

Cladding systems design (Construction and

Finishing materials).

The paper will spotlights the fourth step in the design procedure. It describes the role of the cladding systems design in the design process of protected structures. It presents the various techniques of using construction and finishing materials to reduce the explosion effects (blast waves and fragments) outside and inside structures.

\section{PROTECTION MEASUREMENTS AND EVALUATIONS.}

In landscape design and architecture landscapers and architects usually use subjective scales (harmony, contrast, unity, variety, beauty, ....etc.) to measure the effectiveness of their design. But in the case of protection the matter is different as an objective scale is obviously needed [R5].

For the evaluation of the effectiveness of such new techniques, several methods are used:

a) Finite elements packages (Autodyn 2D, Autodyn 3D. ...etc.).

b) Scale modeling tests.

c) Full scale modeling tests.

\section{CHARGES.}

Explosives charge weight varies according to targets [R4]. Its average is around $500 \mathrm{~kg}$ up to one ton when using vans or trucks and around $250 \mathrm{~kg}$ when using cars. Vehicle type is considered as an important factor in determining the charge size and by turns its weight.

\section{PROTECTION APPROACHES USING NEW CONSTRUCTION AND FINISHING MATERIALS.}

The integration process of using new cladding systems and new construction materials in a special design technique will minimize the effect of the explosion on structures. The success of this fact will maximize especially when the materials and the cladding design can integrate together to give an aesthetic an attractive appearance.

These techniques can be used either in the newly designed structures or even in the existing structures and can be classified into two approaches [R6]:

a) The approach of using windows \& skylight catchers.

b) The approach of using a fill-In masonry materials or metal studs walls. 
Table (1) shows some of the new techniques that are used in both of the two approaches [R ]:

\begin{tabular}{|c|c|c|}
\hline Design Approach & Technique title & Technique description \\
\hline \multirow[b]{2}{*}{ First Approach } & I- $\quad$ Louver Catcher System. & Debris catcher. \\
\hline & II- Fabric catcher system. & Debris catcher. \\
\hline \multirow{2}{*}{$\begin{array}{l}\text { Windows \& skylight } \\
\text { catchers. }\end{array}$} & III- Cable Catcher System. & Debris catcher. \\
\hline & IV- Window retrofit concept. & $\begin{array}{l}\text { Uses ductility to prevent } \\
\text { failure. }\end{array}$ \\
\hline \multirow{4}{*}{$\begin{array}{l}\text { Second Approach } \\
\text { Fill-In masonry } \\
\text { materials or metal studs } \\
\text { walls. }\end{array}$} & V- Steel plates System. & Ductile catcher system. \\
\hline & VI- Polyurethane foam panels. & $\begin{array}{l}\text { Uses stiffness and ductility } \\
\text { to prevent failure. }\end{array}$ \\
\hline & VII- Kevlar laminates system. & $\begin{array}{l}\text { Ductile reinforcement, to } \\
\text { prevent wall damage.. }\end{array}$ \\
\hline & VIII- Sure-Board ${ }^{\mathrm{TH}}$ panels. & Ductile catcher system. \\
\hline
\end{tabular}

Table (1) : Various approaches and techniques of using new construction and finishing materials in protection.

a) The approach of using windows \& skylight catchers:

This approach depends on using a protective material either in front of or pasted on glass areas (windows, skylights, curtain walls ...etc), or even solid surfaces (masonry works, wood works, concrete works, etc...) as a barrier to prevent debris or blast waves from entering the exposed space in case of detonations. 


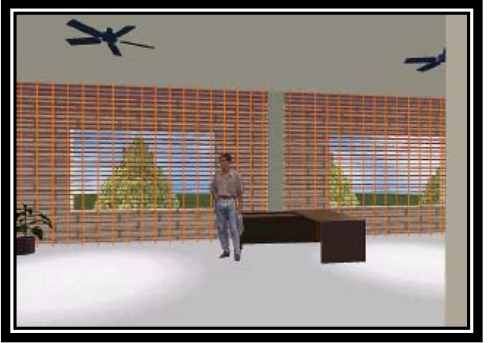

Fig. (1): Louver catcher system to prevent exterior walls or debris from penetrating internally

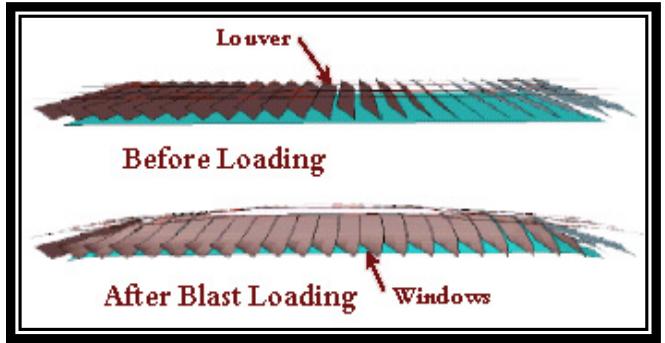

Fig. (2): Analytic model of louver system and window

\section{Concept and Configuration:}

- The louvers are attached to a flexible support that may be anchored to the floors of the building or to adjacent walls if strong enough, or nearby columns.

- Initially the louvers were open in the model and as the window strikes the louvers, it forces them to close.

- An anti-shatter film, to ensure that the fragments are sufficiently large to be held by catcher system, is used to line the inner surface of the window to minimize debris and to allow the interaction of the window and the catcher system to force the louvers closed.

\section{Applications:}

Louvers, looking like standard blinds, are deployed to cover a window protecting the room's occupants from glass shards.

Technique II : Fabric Catcher System
Concept and Configuration
High strength transparent fabric such as high tenacity polyamides and aramids are deployed
to cover the windows protecting the room's occupants from glass shards.
The fabric is attached to a flexible support frame which must have the essential feature of
behaving plastically and yielding both in- and out-of- the fabric's plane to minimize the fabric
stresses.
The support frame may be anchored to the floors of the building or to adjacent columns and
walls by ductile anchorage.
Applications:
Fabric catcher system is already widely used by architects for shading as it may be finished in a
large variety of colors and styles.




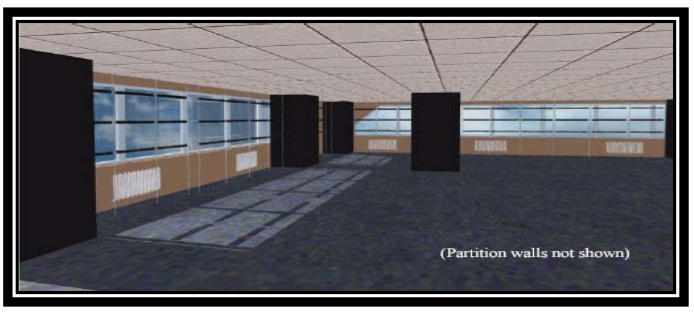

Fig. (5) Interior view for cable system in place.

\section{Concept and Configuration:}

- Cable catcher system consists of an orthogonal grid of cables that is installed behind the windows. This grid catches the windows as they were propelled towards the interior due to the blast pressures.

- Anti-shatter film is applied to both interior and exterior panes of the glass to remain essentially integration of panes, and light gage steel sheeting is applied to the walls above and below the windows.

- Vertical aluminum strips bonded to the interior of the glass panes, intended to provide solid bearing contact upon impact with the horizontal cables to prevent shredding of the anti-shatter film and loss of panel integrity.

\section{Applications:}

Cable catcher system is effective without severely hindering the building's architectural functionality or aesthetic appeal.

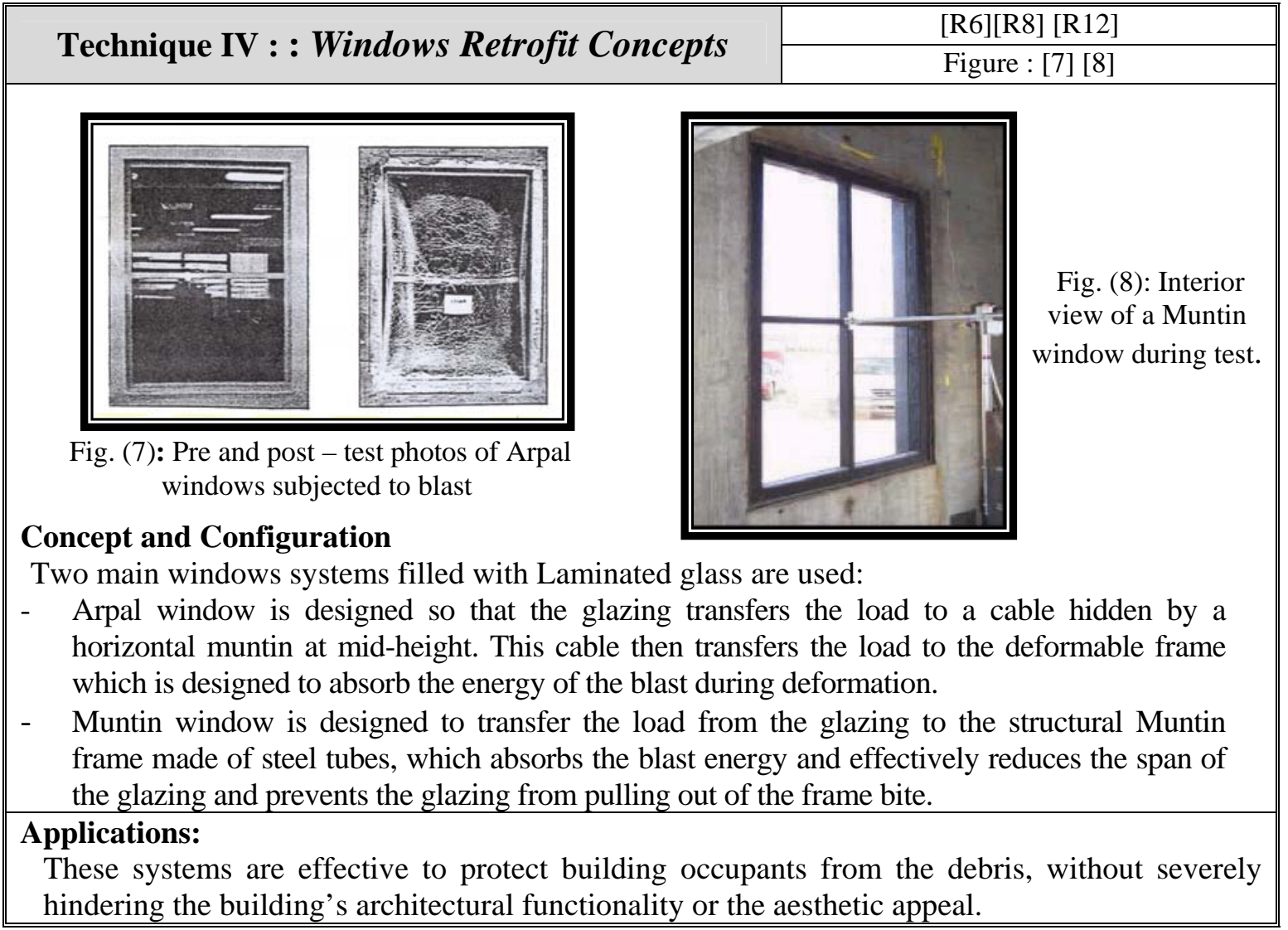

\section{b) The approach of using a fill-In masonry materials or metal studs walls:}


This approach depends on using a protective material either in front of, pasted on or lining solid surfaces (masonry works, wood works, concrete works, etc...) as a reinforcement to retrofit and prevent them from being collapsed or shifted in case of detonations.

Technique V : Steel plate System
Fig. (9) Steel plate prevents most of the
debris from reaching beyond it.
-
A steel plate is used to retrofit the wall which had no openings and no glass design. So, it can
be used with the building abuts an adjacent parking garage.
The steel plate includes a thin (1/8 inch) steel plate attached to the edge beams at top and
bottom with multiple rows of fasteners. The space between the steel and the existing brick
wall is filled with pump-able lightweight concrete or foam blocks which are highly crushable.
This crushable layer serves as a means of attenuating the shear load at the anchorage of the
steel plate, and it converts the highly localized and non-uniform impact loads from the brick
debris into a much more uniform and homogeneous spatial load distribution.
Applications:
Architecturally, this design is attractive because it subtracts very little from the usable floor space
of the building, and the metal surface can be covered with fabric wall covering for aesthetic appeal.

\section{Technique VI : : Polyurethane foam Panels}

\begin{tabular}{|c|}
\hline [R6][R9][R10] [R11] \\
\hline Figure : [11] \\
\hline
\end{tabular}

Fig. (11): Large and Small anchorage panel of Polyurethane foam.

\section{Concept and Configuration}

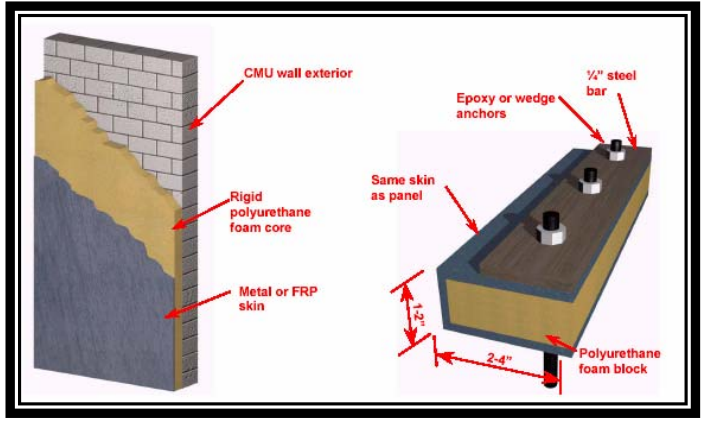

- Polyurethane foam is used to retrofit the non-load bearing walls of conventional buildings and to improve their resistance to air blast and ballistic fragments

- A $4 \times 10$-foot panel constructed with a core of rigid polyurethane foam with a sheet of metal skin attached to one face of the core. The other face of the core is glued to the wall to be retrofitted.

\section{Applications:}

Architecturally, this design is attractive because the metal surface can be covered with fabric wall covering for aesthetic appeal. 


\begin{tabular}{|l}
\hline Kig. (12) Photo of \\
Kevlar laminates.. \\
Concept and Configuration: \\
Kevlars' laminates is a type of fabrics made from a liquid crystalline polymer that by spinning \\
process changes to a strong fiber. \\
A Kevlar laminate is glued to the wall with polyurethane and tied to the diaphragms without \\
an anchorage device. \\
Applications: \\
Architecturally, Kevlar laminate may be finished in a large variety of colors and styles to give a \\
final attractive wall coat.
\end{tabular}

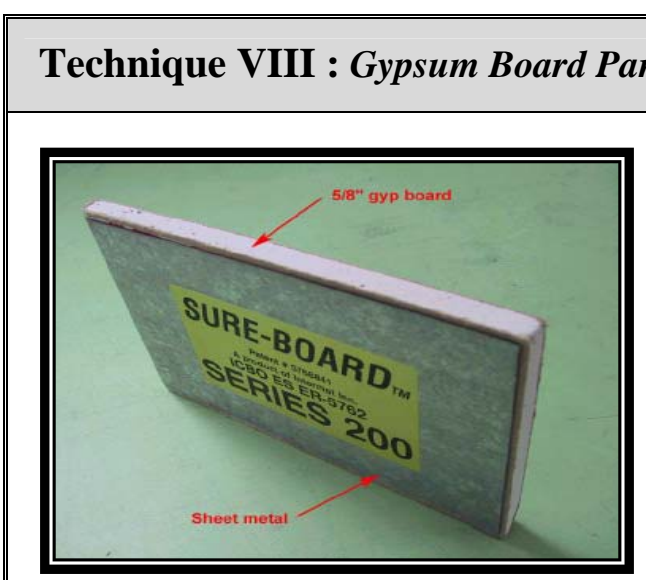

Fig. (14) Photo of hardend gypsum board (Sure-Board ${ }^{\mathrm{TM}}$ ).

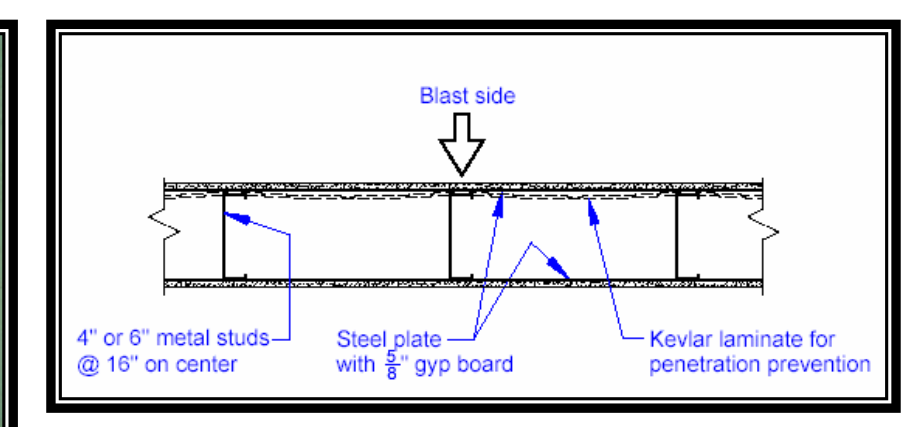

Fig. (15) Section of Sure-Board ${ }^{\mathrm{TM}}$ stud wall (Kevlar on hlast side nrovides ontional hallistic nrotection).

\section{Concept and Configuration}

- Sure-Board ${ }^{\mathrm{TM}}$ panels consist of two ply laminated compossite panel comprised of gypson board, sheet steel and adhesive.

- $\quad$ A $4 \times 15$-foot panel of Sure-Board ${ }^{\mathrm{TM}}$ is added to the inner surface of a metal or wooden stud wall. It could be attached directly to the existing wall, overlaying inner drywall panel.

- $\quad$ Sure-Board ${ }^{\mathrm{TM}}$ may be used for one or both sides of wall. Kevlar laminate may be added to the exterior face to provide added wall stiffness and capacity as well as fragment protection.

\section{Applications:}

The finishing procedures for Sure-Board ${ }^{\mathrm{TM}}$ are the same as for standard gypsum board.

\section{CONCLUSIONS.}


From the previous study, the following facts can be deduced: -

a) The traditional techniques of protecting structures against terrorism and public disorder despite their validity have some disadvantages:-

i. Oppose the aspiration of the architect.

ii. Impede the activities, which the structure is designed to accommodate.

iii. Incur high construction costs, which may not be in function in case if the structure will not suffer any kind of threat.

iv. Psychologically influence the structure's users as they may convert the building to a type of fort or casemate.

b) A new design process hierarchy emerged that based on a joint responsibility between several specialists, each has a role in minimizing the expected threat on structures. And by combining all these roles the threat will reach its minimum level.

c) The new design process hierarchy of protecting structures against explosion takes the following form.

i. The landscape design.

ii. The overall architectural design concept of design.

iii. Civil analysis and design.

iv. Cladding systems design (Construction and Finishing materials).

d) Protection using new construction and finishing materials are classified into two main approaches:

i. The approach of using windows \& skylight catchers.

ii. The approach of using a fill-In masonry materials or metal studs walls.

e) Throughout each design approach, several protection techniques can be investigated and used Table (1).

f) The approach of using windows \& skylight catchers depends on using a protective material either in front of or pasted on glass areas and solid as a barrier to prevent debris or blast waves from entering the exposed space in case of detonations.

g) The approach of using a fill-In masonry materials or metal studs walls depends on using a protective material either in front of, pasted on or lining solid surfaces as a reinforcement to retrofit and prevent them from being collapsed or shifted in case of detonations.

h) The new techniques can offer a significant reduction in the effect of the blast waves and fragments on the structures without affecting the functionality.

i) The new techniques can be used for both existing and new structures.

j) The effect of the threat on structure is reduced to reach the minimum value by combing all/some of the new techniques.

\section{REFERENCES.}


[1] C. L. Elliot, The Defence of buildings against Terrorism and Disorder, A design philosophy for the construction of ordinary buildings and installations to resist terrorism and disorder, M Phil thesis, Cranfield University, RMCS, UK, 1989-1990.

[2] Ehab Hanafi Mahmoud, Mitigation of blast waves in urban Environments, $\mathrm{PhD}$ thesis, Military Technical Collage, Cairo, Egypt, 2003.

[3] M.A. Barakat \& J. G. Hetheringtion, An architectural approach towards reducing the effects of blast waves and fragments on structures, Proceedings of the 2nd Asia-pacific conference on shock and impact loads on structures, Melbourne, Australia, 25-27 November 1997.

[4] Mohamed Ali Barakat, The Architecture of Protected Structures, PhD thesis, Cranfield University- RMCS, October, UK, 1998.

[5] M.A. Barakat \& J. G. Hetheringtion, New architectural-forms to reduce the effects of blast waves and fragments on structures, proceedings of the 5th International conference of structures under shock and impact, Thessaloniki, Greece, 25-27 November 1997.

[6] Hesham Ashraf El kadi, The Architectural treatments for protecting structures, MSc thesis, Military Technical Collage, Cairo, Egypt, 2003.

[7] John E. Crawford, Daniele Pelessone, David D. Bogosian and Anthony A.Ronca, Retrofits for Existing Windows to Protect Occupants from Injurious Debris Due to Bombing, $71^{\text {st }}$ Shock \& Vibration Symposium, Arlington, VA, USA, November. 2000.

[8] David D. Bogosian and John E. Crawford, Energy Absorbing Retrofit Systems for Mitigating Blast Effects on Occupants of Conventional Buildings, $29^{\text {th }}$ Explosives Safety Seminar, New Orleans, LA, USA, July 2000.

[9] John E. Crawford, Addressing Force Protection Issues More Effectively, The Society of American Military Engineers Symposium on Comprehensive Force Protection, Charleston, SC, USA, November 2001.

[10] John E. Crawford, Modeling Blast-Resistant Protection Systems Composed of Polymers and Fabric, ASM, October 2002

[11] J. E. Crawford \& K. B. Morrill, New Highly Ductile Designs for Preventing Injurious Wall Debris due to Terrorist Bombing, International conference on Protection Of Structure Against Hazards, Singapore, 14-15 Nov. 2002.

[12] R.L. Hall and L.K. Davis, US Armed Corps of Engineers, USA, Terrorist Threats Against The Pentagon, International conference on Protection Of Structure Against Hazards, Singapore, 14-15 Nov. 2002. 